\title{
Pengaruh Budaya Organisasi Terhadap Employee Engagement pada Karyawan BAAK Universitas XYZ di Jakarta
}

\author{
Melkianus Albin Tabun \\ tabunmelkianus@gmail.com \\ Program Pasca-Sarjana Manajemen \\ Universitas Pelita Harapan, Jakarta-Indonesia
}

\begin{abstract}
This research was conducted on employees of the Bureau of Academic Administration and Student Affairs (BAAK) at XYZ University in Jakarta in order to examine the effect of organizational culture on employee engagement. The population in this study were all employees of BAAKXYZ University in Jakarta, amounting to 35 people. The sampling technique used was the saturated sampling technique, because the population in this study was relatively small so that all the employees of BAAK XYZ University in Jakarta, totaling 35 employees, were selected to be the sample. The data collection method uses an online questionnaire (google form). Methods of data analysis using descriptive analysis and simple linear regression analysis. The results of the analysis are: the results of descriptive analysis of the variables of organizational culture and employee engagement show in average high score, meaning that the better the organizational culture of employees, the higher the employee engagement. The results of hypothesis testing (ttest) show that organizational culture has a positive and significant effect on employee engagement at BAAK XYZ University employees in Jakarta, therefore, aspects related to employee engagement need to be considered because the employee who is engaged is someone who thinks positively about his job; believe in what it is doing and identify it with the organization; work actively to make things better; treat others with respect, and help colleagues to work more effectively; reliable, and goes beyond the requirements of the job; see the bigger picture, sometimes even at the personal expense for the benefit of the organization; follow developments in their fields; seek, and are allowed to improve organizational performance.
\end{abstract}

\section{Keywords: Organizational Culture; Employee Engagement}

\section{Pendahuluan}

Employee engagement didefinisikan sebagai keterikatan anggota organisasi dengan organisasi itu sendiri bukan hanya secara fisik, kognitif tetapi juga secara emosional dalam hal kinerjanya (Albrecht, 2010). Employee engagement atau keterikatan karyawan saat ini menjadi isu yang sangat penting bagi suatu organisasi. Ketika karyawan memiliki engagement yang kuat dengan perusahaan akan ada perasaan positif dan intens yang meningkat diantara mereka untuk mengerahkan upaya terbaiknya untuk keberhasilan organisasi (Othman dkk., 2017) Keterlibatan karyawan (employee engagement), yaitu keterlibatan, kepuasan, dan antusiasme individual dengan pekerjaan yang mereka lakukan (Robbins \& Judge, 2008). Sedangkan menurut Armstrong (2008) mengatakan bahwa orang-orang yang engage di tempat kerja bersikap positif, tertarik, dan bahkan bersemangat tentang pekerjaan mereka dan siap bekerja lebih keras untuk menyelesaikannya dengan kemampuan terbaik mereka. Lanjut Armstrong bahwa istilah employee engagement mengacu pada sejauh mana karyawan melakukan upaya diskresioner ke dalam pekerjaan mereka, di luar batas minimum untuk menyelesaikan pekerjaan, dalam bentuk waktu ekstra, kekuatan otak atau energi. Hal tersebut mendorong potensi karyawan untuk memberikan kontribusi terbaik yang bisa mereka berikan kepada perusahaan tempat karyawan bekerja. 
Employee engagement yang dirasakan oleh karyawan dipengaruhi oleh berbagai aspek, seperti pekerjaan itu sendiri, lingkungan kerja, kepemimpinan dalam organisasi, kesempatan untuk berkontribusi dan berkembang. Dari beberapa aspek tersebut, lingkungan kerja yang sangat mempengaruhi employee engagement karena lingkungan kerja berfokus pada mengembangkan sebuah budaya yang bisa mendorong adanya sikap positif untuk bekerja dan hal-hal yang dapat membuat karyawan merasa nyaman dan aman (Armstrong, 2008). Hal ini menunjukkan bahwa budaya organisasi merupakan salah satu faktor yang sangat penting untuk diperhatikan agar dapat meningkatkan employee engagement dari waktu ke waktu. Karena budaya organisasi merupakan ciri khas yang dimiliki perusahaan yang dapat membedakan perusahaan tersebut dengan perusahaan lainnya.

Menurut Robbins \& Judge (2002), budaya organisasi merujuk kepada suatu sistem pengertian bersama yang dipegang oleh anggota-anggota suatu organisasi yang membedakan organisasi tersebut dari organisasi lainnya. Sedangkan menurut Kreitner \& Kinicki (2005), budaya organisasi adalah satu wujud anggapan yang dimiliki, diterima secara implisit oleh kelompok dan menentukan bagaimana kelompok tersebut rasakan, pikirkan, dan bereaksi terhadap lingkungan yang beraneka ragam. Sedangkan menurut (Akbar, 2013) bahwa budaya organisasi yang ada di dalam perusahaan terbagi menjadi dua konsep dari sudut pandang karyawan perusahaan. Konsep sudut pandang budaya tersebut yaitu budaya yang sesuai harapan dan budaya pada kenyataannya. Budaya yang sesuai harapan adalah budaya yang diinginkan oleh karyawan perusahaan dan budaya yang tidak sesuai harapan adalah budaya yang tidak seperti diinginkan oleh karyawan perusahaan.

Universitas XYZ adalah salah satu sektor yang bergerak dalam bidang pendidikan di Jakarta - Indonesia. Kemajuan dan kesuksesan Universitas XYZ ini sangat bergantung pada kerjasama antar department. Salah satu department yang memegang peranan penting di dalam Universitas tersebut adalah Biro Administrasi Akademik dan Kemahasiswaan (BAAK). Departement ini sebagai road map untuk pelaksanaan kegiatan belajar mengajar dosen dan mahasiswa serta aktivitas akademik lainnya, sehingga membutuhkan sumber daya manusia yang berkualitas dan kompeten. Namun tidak hanya sebatas berkualitas dan kompeten akan tetapi membutuhkan sumber daya manusia yang engage di dalam organisasi. Pada tahun 2018-2019, department ini menunjukkan jumlah karyawan yang berhenti/ keluar adalah sebanyak 10 orang. Berikut ini adadalah rumus perhitungan tingkat turnover yang terjadi pada BAAK Universitas XYZ:

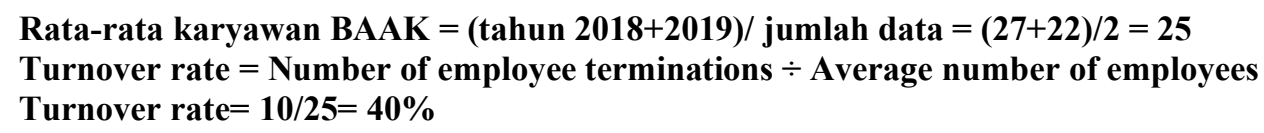

Berdasarkan hasil perhitungan di atas, menunjukkan bahwa tingkat turnover di atas rata-rata yaitu $40 \%$, berarti rata-rata karyawan di BAAK Universitas XYZ tidak engage dengan organisasinya karena data menunjukkan bahwa hampir separuh jumlah karyawan tersebut memilih untuk berhenti/ pergi bekerja di tempat lain dari pada di BAAK Universitas XYZ. Dengan demikian, hal ini menjadi bidang yang menarik untuk ditelaah lebih lanjut sehingga dalam penelitian ini, peneliti mengambil judul tentang Pengaruh Budaya Organisasi Terhadap Employee Engagement Pada Karyawan BAAK Universitas XYZ di Jakarta.

\section{Kajian Literatur}

\section{Employee Engagement}

Menurut Budihardjo (2011) employee engagement merupakan konstruk bermulti dimensional. Ada tiga jenis engagement: (1) emotional jika employee engagement membentuk hubungan yang bermakna dengan karyawan yang lain dan berempati serta peduli dengan perasaan 
karyawan lain; (2) cognitive yaitu jika mereka secara sungguh-sungguh sadar pada misi dan peranannya dalam lingkungan pekerjaannya. c). physical yaitu jika employee engagement bekerja disebabkan oleh faktor-faktor fisikal.

Signifikansi engagement adalah bahwa keterlibatan merupakan inti dari hubungan kerja. Ini tentang apa yang dilakukan orang dan bagaimana mereka berperilaku dalam peran mereka dan apa yang membuat mereka bertindak dengan cara yang memajukan pencapaian tujuan organisasi dan diri mereka sendiri (Armstrong, 2008:141).

Menurut Armstrong (2008) bahwa karyawan yang engage adalah (1) seseorang yang berpikir positif tentang pekerjaannya; (2) percaya pada apa yang dilakukannya dan mengidentifikasinya dengan organisasi; (3) bekerja secara aktif untuk membuat segalanya lebih baik; (4) memperlakukan orang lain dengan hormat, dan membantu rekan kerja untuk bekerja lebih efektif; (5) dapat diandalkan, dan melampaui persyaratan pekerjaan; (6) melihat gambaran yang lebih besar, bahkan terkadang mengeluarkan biaya pribadi untuk kepentingan organisasi; (7) mengikuti perkembangan di bidangnya; (8) mencari, dan diberikan kesempatan untuk meningkatkan kinerja organisasi.

\section{Budaya Organisasi}

Menurut Schein (2010) budaya adalah sesuatu yang abstrak, namun kekuatan yang diciptakan dalam situasi sosial dan organisasi berasal dari budaya yang sangat kuat. Kekuatan budaya sangat kuat karena beroperasi di luar kesadaran kita. Kita perlu memahami mereka bukan hanya karena kekuatan mereka tetapi juga karena mereka membantu menjelaskan banyak pengalaman kita yang membingungkan dan membuat frustrasi dalam kehidupan sosial dan organisasi. Yang terpenting, adalah memahami kekuatan budaya memungkinkan kita memahami diri kita sendiri dengan lebih baik.

Sedangkan budaya organisasi dapat didefinisikan sebagai perangkat sistem nilai-nilai (values), keyakinan-keyakinan (beliefs), asumsi-asumsi (assumptions), atau norma-norma yang telah lama berlaku, disepakati dan diikuti oleh para anggota suatu organisasi sebagai pedoman perilaku dan pemecahan masalah-masalah organisasinya. Budaya organisasi juga disebut budaya perusahaan, yaitu seperangkat nilai-nilai atau norma-norma yang telah relatif lama berlakunya, dianut bersama oleh para anggota organisasi (karyawan) sebagai norma perilaku dalam menyelesaikan masalah-masalah organisasi (perusahaan). Dalam budaya organisasi, terjadi sosialisasi nilai-nilai dan menginternalisasi dalam diri para anggota, menjiwai orang per orang di dalam organisasi. Dengan demikian, maka budaya organisasi merupakan jiwa organisasi dan jiwa para anggota organisasi (Sutrisno, 2010).

Budaya organisasi yang kuat mendukung tujuan-tujuan perusahaan, sebaliknya yang lemah atau negatif menghambat atau bertentangan dengan tujuan-tujuan perusahaan. Dalam suatu perusahaan yang budaya organisasinya kuat, nilai-nilai bersama dipahami secara mendalam, dianut, dan diperjuangkan oleh sebagian besar para anggota organisasi (karyawan perusahaan). Budaya yang kuat dan positif sangat berpengaruh terhadap perilaku dan efektivitas kinerja perusahaan sebagaimana dinyatakan oleh Sutrisno (2010) karena dapat menimbulkan hal-hal berikut: (1) Nilai-nilai kunci yang saling menjalin, tersosialisasikan, menginternalisasi, menjiwai pada para anggota, dan merupakan kekuatan yang tidak tampak; (2) Perilaku-perilaku karyawan secara tak disadari terkendali dan terkoordinasi oleh kekuatan yang informal atau tidak tampak; (3) Para anggota merasa komit dan loyal pada organisasi; (4) Adanya musyawarah dan kebersamaan atau kesertaan dalam hal-hal yang berarti sebagai bentuk partisipasi, pengakuan, dan penghormatan terhadap karyawan; (5) Semua kegiatan berorientasi atau diarahkan kepada misi atau tujuan organisasi; (6) Para karyawan merasa senang, karena diakui dan dihargai martabat dan kontribusinya, yang sangat rewarding; (7) Adanya koordinasi, integrasi, dan konsistensi yang menstabilkan kegiatan-kegiatan perusahaan; (8) Berpengaruh kuat terhadap organisasi dalam tiga aspek yaitu pengarahan perilaku dan kinerja organisasi, penyebarannya pada para anggota organisasi, dan kekuatannya, yaitu menekan para anggota untuk melaksanakan nilai-nilai budaya; (9) Budaya berpengaruh terhadap perilaku individual maupun kelompok. 


\section{Hipotesis Penelitian}

Berdasarkan penelitian (Akbar, 2013) diketahui bahwa budaya organisasi mempengaruhi employee engagement. Apabila budaya perusahaan sesuai dengan ekspektasi karyawan maka engagement dari karyawan akan tinggi, begitu juga sebaliknya apabila budaya dalam perusahaan tersebut tidak sesuai ekspektasi dari karyawan maka engagement dari karyawan akan rendah. Hasil penelitian ini mendukung penelitian sebelumnya dari Lockwood (2007) yang menyatakan bahwa budaya organisasi merupakan salah satu faktor yang mempengaruhi employee engagement. Disamping itu juga, penelitian yang dilakukan oleh (Anugra \& Saragih, 2018) hasil menunjukkan bahwa budaya organisasi mempunyai pengaruh yang signifikan terhadap employee engagement. Dengan demikian, budaya organisasi yang senantiasa mendukung pekerjaan dan perkembangan karyawan dapat membentuk keterlibatan (engagement) karyawan dalam organisasi yaitu perasaan positif dan antusiasme terhadap pekerjaannya. Oleh sebab itu, hipotesis yang digunakan dalam penelitian ini adalah sebagai berikut:

$\mathrm{H}_{1}$ : $\quad$ Budaya organisasi berpengaruh positif dan signifikan terhadap employee engagement pada karyawan BAAK Universitas XYZ di Jakarta.

\section{Metodologi Penelitian}

\section{Tempat Penelitian dan Objek Penelitian}

Tempat penelitian ini di Universitas XYZ di Jakarta. Sedangkan objek dan subyek dalam penelitian ini adalah karyawan BAAK Universitas XYZ di Jakarta.

\section{Jenis Penelitian}

Jenis penelitian yang digunakan dalam penelitian ini adalah penelitian kausal dengan pendekatan kuantitatif. Menurut Setiawan \& Muntaha (2014) penelitian kausal adalah penelitian yang meneliti hubungan sebab-akibat dari suatu fenomena untuk mengukur besarnya hubungan antara dua variabel atau lebih. Penelitian ini didasarkan pada pengujian hipotesis (hypothesis testing) sehingga disebut dengan penelitian kausal, dan menurut sudut pandang waktu penelitian ini termasuk penelitian cross-sectional (Wijaya, 2013). Menurut Suliyanto (2018) penelitian cross section adalah penelitian yang dilakukan dengan pengambilan data pada satu waktu dengan subjek yang berbeda untuk menggambarkan keadaan. Penelitian ini dilakukan pada Juli 2020.

\section{Populasi, Sampel dan Teknik Pengambilan Sampel}

Menurut Suliyanto (2018) populasi merupakan keseluruhan elemen yang hendak diduga karakteristiknya. Sedangkan sampel merupakan bagian populasi yang hendak diuji karakteristiknya. Populasi dalam penelitian ini adalah seluruh karyawan BAAK Universitas XYZ di Jakarta yang berjumlah 35 orang karyawan. Dalam penelitian ini metode pengambilan sampel yang digunakan adalah sampling non probabilitas yaitu semua elemen dalam populasi tidak memiliki kesempatan yang sama untuk dipilih menjadi sampel (Wijaya, 2013) dan dalam teknik pengambilan sampelnya menggunakan teknik sampling jenuh yaitu teknik penentuan sampel dimana setiap anggota populasi dipilih menjadi sampel (Sarjono \& Julianita, 2011), karena populasi yang digunakan relatif kecil yaitu seluruh karyawan BAAK Universitas XYZ di Jakarta yang berjumlah 35 orang karyawan dipilih menjadi sampel dalam penelitian ini.

\section{Jenis Data, Metode Pengumpulan Data dan Skala Pengukuran}

Jenis data yang digunakan dalam penelitian ini adalah data primer yakni mengacu pada informasi yang diperoleh dari tangan pertama oleh peneliti yang berkaitan dengan variabel minat untuk tujuan spesifik studi (Sekaran, 2015). Metode pengumpulan data yang digunakan dalam penelitian ini adalah teknik angket (questionnaire) yakni merupakan metode pengumpulan data yang dilakukan dengan cara membagi daftar pertanyaan kepada responden agar responden tersebut memberikan jawaban (Suliyanto, 2018). Karena hasil penelitian ini akan dianalisis secara kuantitatif, maka skala yang digunakan adalah skala likert. Menurut Suliyanto (2018) skala likert 
digunakan untuk mengukur tanggapan atau respons seseorang tentang objek sosial. Jawaban setiap instrumen mempunyai gradasi dari sangat positif sampai dengan negatif, dimana setiap item diberi pilihan respons yang sifatnya tertutup. Untuk mengukur penerapan budaya organisasi terhadap employee engagement pada karyawan BAAK Universitas XYZ di Jakarta, maka peneliti menggunakan tipe skala likert berikut ini: Sangat Tidak Setuju=1, Tidak Setuju=2, Netral=3, Setuju=4, Sangat Setuju=5.

\section{Definisi Operasional}

Definisi operasional menjelaskan cara tertentu yang digunakan untuk mengoperasionalkan konstruk sehingga memungkinkan bagi peneliti lain untuk melakukan replikasi pengukuran dengan cara yang sama atau mengembangkan cara pengukuran konstruk yang lebih baik (Wijaya, 2013). Dalam penelitian ini, peneliti melakukan replikasi kuesioner sebagaimana ditunjukkan pada tabel definisi operasional di bawah ini:

Tabel 1. Definisi Operasional

\begin{tabular}{|c|c|c|c|c|c|c|}
\hline \multirow[t]{2}{*}{ Variabel } & \multirow[t]{2}{*}{ Indikator } & \multicolumn{5}{|c|}{$\begin{array}{l}\text { Frekuensi } \\
\text { Responden }\end{array}$} \\
\hline & & 1 & 2 & 3 & 4 & 5 \\
\hline \multirow[t]{10}{*}{$\begin{array}{l}\text { Budaya } \\
\text { Organisasi }\end{array}$} & $\begin{array}{l}\text { Di kantor saya pembagian tugas sudah ditetapkan dengan } \\
\text { jelas. }\end{array}$ & & & & & \\
\hline & $\begin{array}{l}\text { Di kantor saya masing-masing bagian bekerja secara } \\
\text { terkoordinasi. }\end{array}$ & & & & & \\
\hline & $\begin{array}{l}\text { 3. Jika terjadi masalah di organisasi saya dapat mengandalkan } \\
\text { dukungan pimpinan saya. }\end{array}$ & & & & & \\
\hline & $\begin{array}{l}\text { 4. Pimpinan saya mendukung aktivitas dan usaha kerja di kantor } \\
\text { saya. }\end{array}$ & & & & & \\
\hline & 5. Kesuksesan kantor sangat penting bagi saya. & & & & & \\
\hline & 6. Saya melakukan yang terbaik demi kesuksesan kantor. & & & & & \\
\hline & Di kantor saya, penghargaan didasarkan pada kinerja. & & & & & \\
\hline & Penghargaan saya sesuai dengan kinerja saya. & & & & & \\
\hline & $\begin{array}{l}\text { Di kantor saya, penghargaan didasarkan pada hubungan dan } \\
\text { koneksi. }\end{array}$ & & & & & \\
\hline & $\begin{array}{ll}10 & \begin{array}{l}\text { Pimpinan di kantor saya mendengar pendapat karyawan } \\
\text { meskipun tidak setuju dengan pendapat mereka. }\end{array} \\
\end{array}$ & & & & & \\
\hline \multirow{10}{*}{$\begin{array}{l}\text { Employee } \\
\text { Engagement }\end{array}$} & Saya selalu bersemangat untuk pergi bekerja setiap harinya. & & & & & \\
\hline & 2 Saya selalu bersemangat ketika sedang bekerja. & & & & & \\
\hline & $\begin{array}{l}3 \text { Saya dapat bekerja dalam jangka waktu yang lama pada saat } \\
\text { tertentu. }\end{array}$ & & & & & \\
\hline & Pekerjaan saya merupakan sumber kebanggaan bagi diri saya. & & & & & \\
\hline & Saya antusias dengan pekerjaan saya. & & & & & \\
\hline & Saya bangga dengan pekerjaan yang saya lakukan. & & & & & \\
\hline & Saya merasa pekerjaan yang saya lakukan sangat bermakna. & & & & & \\
\hline & Saya merasa bahagia ketika sedang bekerja. & & & & & \\
\hline & Saya merasa terikat dengan pekerjaan saya. & & & & & \\
\hline & 10 Saya merasa senang ketika bekerja dalam waktu yang lama. & & & & & \\
\hline
\end{tabular}

Sumber : Khairunisa (2018)

\section{Uji Validitas dan Reliabilitas}

Validitas merupakan proses pengukuran untuk menguji kecermatan butir-butir dalam daftar pertanyaan untuk melakukan fungsi ukurnya, semakin kecil varians kesalahan, semakin valid alat ukurnya (Wijaya, 2013).

Untuk mengetahui konsistensi dan akurasi data yang dikumpulkan dari penggunaan instrumen dilakukan uji validitas dengan menggunakan korelasi product moment. Suatu skala pengukuran disebut valid bila ia melakukan apa yang seharusnya dilakukan dan mengukur apa yang seharusnya diukur. Bila skala pengukuran tidak valid maka ia tidak bermanfaat bagi peneliti 
karena tidak mengukur apa yang seharusnya diukur atau melakukan apa yang seharusnya dilakukan. Pada penelitian ini validitas yang diuji adalah validitas konstuk (construct validity) dengan mengkorelasikan skor masing-masing butir dengan skor total. Skor total sendiri adalah skor yang didapat dari penjumlahan skor butir untuk instrumen tersebut.

Ketentuan: dengan taraf signifikan $(\alpha)=0,05$, jika $r_{\text {hitung }}>r_{\text {tabel }}$ maka kuisioner sebagai alat pengukur dikatakan valid atau ada korelasi yang nyata antara kedua variabel tersebut.

Reliabilitas merupakan proses pengukuran yang menunjukkan suatu pengukuran dapat memberikan hasil yang relatif sama jika dilakukan pengukuran ulang terhadap subyek yang sama, semakin kecil perbedaan hasil yang diperoleh, semakin andal hasil tesnya. Ukuran reliabilitas dapat menggunakan koefisien Alpha atau metode Cronbach Alpha. Syarat reliable adalah jika memiliki nilai Alpha $>0,70$ (Wijaya, 2013).

\section{Analisis Data}

Analisis data adalah proses mengolah data dan penginterpretasian hasil pengolahan data. Jenis analisis data yang digunakan dalam penelitian ini adalah analisis deskriptif dan analisis kuantitatif.

Analisis deskriptif adalah analisis yang menekankan pada pembahasan data-data dan subjek penelitian dengan menyajikan data-data secara sistematik dan tidak menyimpulkan hasil penelitian (Priyatno, 2008). Tujuan dari analisis deskriptif ini adalah untuk menganalisis data yang berhubungan dengan karakteristik responden yang meliputi jenis kelamin, usia, analisis deskriptif terhadap variabel penelitian, dan lain sebagainya.

Menurut Ermawati \& Ardana (2018) menyatakan bahwa untuk mendeskripsikan penilaian responden terhadap variabel-variabel penelitian yang digunakan perlu dilakukan penentuan distribusi frekuensi berdasarkan nilai intervalnya. Untuk menentukan nilai intervalnya dengan menggunakan nilai skor, nilai maksimal sebesar 5 dan minimal 1, rumusnya adalah sebagai berikut:

$$
\begin{aligned}
& \text { Nilai Interval }=\frac{(\text { Nilai batas tertinggi-Nilai batas terendah })}{\text { Jumlah Kelas }} \\
& \text { Nilai Interval }=\frac{5-1}{5}=0,8
\end{aligned}
$$

Berdasarkan hasil interval range di atas, maka diperoleh rata-rata skor pada setiap variabel penelitian adalah sebagai berikut:

Tabel 2. Kriteria Skor Variabel Penelitian

\begin{tabular}{|l|l|l|}
\hline Nilai Skor & Budaya Organisasi & Employee Engagement \\
\hline $1,00-1,80$ & Sangat rendah & Sangat rendah \\
\hline $1,81-2,60$ & Rendah & Rendah \\
\hline $2,61-3,40$ & Sedang & Sedang \\
\hline $3,41-4,20$ & Kuat & Tinggi \\
\hline $4,21-5,00$ & Sangat Kuat & Sangat tinggi \\
\hline
\end{tabular}

Sumber: Ermawati \& Ardana (2018).

Sedangkan analisis kuantitatif merupakan analisis yang digunakan untuk data-data yang berbentuk angka yang dapat diukur atau dihitung. Tujuan analisis kuantitatif dalam penelitian ini adalah untuk mengetahui seberapa besar pengaruh variabel independen terhadap variabel dependen. Dalam penelitian ini, peneliti menggunakan analisis regresi linear sederhana. Menurut Wijaya (2013) regresi linear sederhana digunakan apabila variabel dependen dipengaruhi hanya oleh satu variabel independen. Persamaan matematis untuk regresi linear sederhana adalah

$$
\mathrm{Y}=\mathrm{a}+\beta \mathrm{X}+\varepsilon
$$


Keterangan:

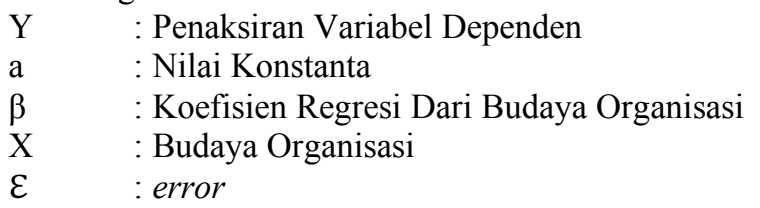

Untuk mengetahui serta menentukan arah besarnya koefisien antara variabel independen dengan variabel dependen, maka digunakan teknik bantuan SPSS versi 25.0 for windows.

\section{Pengujian Hipotesis Dengan Menggunakan Uji t}

Menurut Priyatno (2008) uji parsial (Uji t) digunakan untuk mengetahui apakah dalam model regresi variabel independen (X) secara parsial berpengaruh signifikan terhadap variabel dependen (Y).

\section{Koefisien Determinasi $\left(\mathbf{R}^{2}\right)$}

Menurut Priyatno (2008) koefisien determinasi $\left(\mathrm{R}^{2}\right)$ digunakan untuk mengetahui seberapa besar persentase sumbangan pengaruh variabel independen $(\mathrm{X})$ terhadap variabel dependen $(\mathrm{Y})$.

\section{Isi Makalah}

Dalam penelitian ini, peneliti telah menyebarkan kuesioner melalui google form sejak tanggal 15-20 Mei 2020 kepada karyawan BAAK Universitas XYZ di Jakarta. Selanjutnya peneliti melakukan analisis secara statistik dengan menggunakan program SPSS versi 25.0 sebagaimana diuraikan hasilnya di bawah ini.

\section{Analisis Deskriptif}

Berdasarkan hasil analisis deskriptif terhadap variabel budaya organisasi dan employee engagement sebagaimana ditunjukkan pada tabel di bawah ini:

Tabel 3. Penilaian Responden Terhadap Variabel Budaya Organisasi \& Employee Engagement

\begin{tabular}{|c|c|c|c|c|c|c|c|}
\hline \multirow{2}{*}{ No } & \multirow{2}{*}{ Indikator } & \multicolumn{5}{|c|}{ Frekuensi Responden } & \multirow{2}{*}{$\begin{array}{c}\text { Skor } \\
\text { Rata- } \\
\text { rata }\end{array}$} \\
\hline & & 1 & 2 & 3 & 4 & 5 & \\
\hline 1. & Di kantor saya pembagian tugas sudah ditetapkan dengan jelas. & 0 & 1 & 6 & 19 & 9 & 4.03 \\
\hline 2. & $\begin{array}{l}\text { Di kantor saya masing-masing bagian bekerja secara } \\
\text { terkoordinasi. }\end{array}$ & 0 & 1 & 2 & 21 & 11 & 4.20 \\
\hline 3. & $\begin{array}{l}\text { Jika terjadi masalah di organisasi saya dapat mengandalkan } \\
\text { dukungan pimpinan saya. }\end{array}$ & 0 & 1 & 7 & 18 & 9 & 4.00 \\
\hline 4. & $\begin{array}{l}\text { Pimpinan saya mendukung aktivitas dan usaha kerja di kantor } \\
\text { saya. }\end{array}$ & 0 & 0 & 8 & 16 & 11 & 4.09 \\
\hline 5. & Kesuksesan kantor sangat penting bagi saya. & 0 & 0 & 4 & 18 & 13 & 4.26 \\
\hline 6. & Saya melakukan yang terbaik demi kesuksesan kantor. & 0 & 0 & 0 & 18 & 17 & 4.49 \\
\hline 7 & Di kantor saya, penghargaan didasarkan pada kinerja. & 1 & 5 & 19 & 7 & 3 & 3.17 \\
\hline 8 & Penghargaan saya sesuai dengan kinerja saya. & 0 & 4 & 16 & 13 & 2 & 3.37 \\
\hline 9 & $\begin{array}{l}\text { Di kantor saya, penghargaan didasarkan pada hubungan dan } \\
\text { koneksi. }\end{array}$ & 5 & 7 & 16 & 4 & 3 & 2.80 \\
\hline 10 & $\begin{array}{l}\text { Pimpinan di kantor saya mendengar pendapat karyawan } \\
\text { meskipun tidak setuju dengan pendapat mereka. }\end{array}$ & 0 & 3 & 10 & 19 & 3 & 3.63 \\
\hline \multicolumn{7}{|c|}{ Variabel Budaya Organisasi } & 3.80 \\
\hline 1 & Saya selalu bersemangat untuk pergi bekerja setiap harinya. & 0 & 0 & 7 & 21 & 7 & 4.00 \\
\hline 2 & Saya selalu bersemangat ketika sedang bekerja. & 0 & 0 & 5 & 24 & 6 & 4.03 \\
\hline 3 & $\begin{array}{l}\text { Saya dapat bekerja dalam jangka waktu yang lama pada saat } \\
\text { tertentu. }\end{array}$ & 0 & 0 & 6 & 19 & 10 & 4.11 \\
\hline
\end{tabular}




\begin{tabular}{|c|c|c|c|c|c|c|c|}
\hline \multirow{2}{*}{ No } & \multirow{2}{*}{ Indikator } & \multicolumn{5}{|c|}{ Frekuensi Responden } & \multirow{2}{*}{$\begin{array}{c}\text { Skor } \\
\text { Rata- } \\
\text { rata }\end{array}$} \\
\hline & & 1 & 2 & 3 & 4 & 5 & \\
\hline 4 & Pekerjaan saya merupakan sumber kebanggaan bagi diri saya. & 0 & 0 & 6 & 26 & 3 & 3.91 \\
\hline 5 & Saya antusias dengan pekerjaan saya. & 0 & 0 & 5 & 27 & 3 & 3.94 \\
\hline 6 & Saya bangga dengan pekerjaan yang saya lakukan. & 0 & 0 & 6 & 22 & 7 & 4.03 \\
\hline 7 & Saya merasa pekerjaan yang saya lakukan sangat bermakna. & 0 & 0 & 3 & 22 & 10 & 4.20 \\
\hline 8 & Saya merasa bahagia ketika sedang bekerja. & 0 & 0 & 9 & 20 & 6 & 3.91 \\
\hline 9 & Saya merasa terikat dengan pekerjaan saya. & 0 & 3 & 10 & 18 & 4 & 3.66 \\
\hline 10 & Saya merasa senang ketika bekerja dalam waktu yang lama. & 0 & 4 & 13 & 15 & 3 & 3.49 \\
\hline & Variabel Employee Engagement & & & & & & 3.93 \\
\hline
\end{tabular}

Sumber: Data Primer Diolah 2020.

Skor rata-rata penilaian responden terhadap budaya organisasi sebesar 3,80, yang berarti bahwa jumlah responden sebagian besar menjawab setuju pada kuesioner budaya organisasi. Skor rata-rata tertinggi penilaian responden pada variabel budaya organisasi yaitu pada pertanyaan nomor ke-6 dengan skor sebesar 4,49 yang menyatakan bahwa karyawan melakukan yang terbaik demi kesuksesan kantor. Sedangkan skor rata-rata terendah pada variabel budaya organisasi yaitu pada pertanyaan nomor ke-9 dengan skor sebesar 2,80 yang menyatakan bahwa penghargaan karyawan didasarkan pada hubungan dan koneksi. Maka, pengaruh budaya organisasi terhadap employee engagement pada karyawan BAAK Universitas XYZ di Jakarta sudah kuat. Hal ini menunjukkan bawah perusahaan telah menerapkan budaya organisasi ini dengan baik kepada karyawan sehingga semakin baik penerapan budaya organisasi maka semakin tinggi pula employee engagement.

Sedangkan penilaian responden terhadap variabel employee engagement menunjukkan skor rata-rata employee engagement sebesar 3,93, yang berarti sebagian besar responden menjawab setuju terhadap variabel employee engagement. Skor rata-rata tertinggi penilaian responden pada variabel employee engagement yaitu pada pertanyaan nomor ke-7 dengan skor sebesar 4,20 yang menyatakan bahwa karyawan merasa pekerjaan yang dilakukan sangat bermakna bagi organisasi. Sedangkan skor rata-rata terendah pada variabel employee engagement yaitu pada pertanyaan ke-10 dengan skor sebesar 3,49 yang menyatakan bahwa karyawan merasa senang ketika bekerja dalam waktu yang lama. Hal ini menunjukkan bahwa rata-rata karyawan BAAK Universitas XYZ di Jakarta sudah engage dengan pekerjaannya.

Hal ini sejalan dengan pendapat Armstrong (2008) bahwa karyawan yang engage adalah seseorang yang berpikir positif tentang pekerjaannya; percaya pada apa yang dilakukannya dan mengidentifikasinya dengan organisasi; bekerja secara aktif untuk membuat segalanya lebih baik; memperlakukan orang lain dengan hormat, dan membantu rekan kerja untuk bekerja lebih efektif; dapat diandalkan, dan melampaui persyaratan pekerjaan; melihat gambaran yang lebih besar, bahkan terkadang mengeluarkan biaya pribadi untuk kepentingan organisasi; mengikuti perkembangan di bidangnya; mencari, dan diberikan kesempatan untuk meningkatkan kinerja organisasi.

\section{Hasil Uji Validitas}

Uji instrumen yang dilakukan dalam penelitian ini ditujukan pada 35 responden dengan taraf signifikansi $5 \%$, dengan $n=35$ ( $n$ adalah jumlah sampel), $d f=n-2$, atau $35-2=33$ dan $p=0,05$ maka didapat $r_{\text {tabel }}=0,3338$.

Berdasarkan hasil uji validitas menunjukkan bahwa hanya 9 item dari variabel budaya organisasi yang dinyatakan valid karena nilai $r_{\text {hitung }}>r_{\text {tabel }}(0,3338)$ sehingga indikator-indikator tersebut dapat digunakan dalam penelitian ini, sedangkan satu item dari variabel budaya organisasi yaitu item ke-9 tidak valid karena nilai $\mathrm{r}_{\text {hitung }}(-0,098)<\mathrm{r}_{\text {tabel }}(0,3338)$ sehingga indikator tersebut di-drop dari penelitian ini. Untuk hasil uji validitas yang dilakukan pada variabel employee engagement (Y), diperoleh hasil bahwa 10 item pernyataan dari variabel employee 
engagement $(\mathrm{Y})$ dinyatakan valid karena nilai $\mathrm{r}_{\text {hitung }}>\mathrm{r}_{\text {tabel }}(0,3338)$ sehingga indikator-indikator tersebut layak untuk digunakan dalam penelitian ini.

\section{Hasil Uji Reliabilitas}

Pengujian reliabilitas dalam penelitian ini dilakukan dengan menghitung besarnya nilai Cronbach's Alpha dari masing-masing variabel yang diuji. Apabila nilai Cronbach's Alpha lebih besar dari 0,70, maka kuesioner sebagai alat pengukur dinyatakan reliabel. Jika nilai Cronbach's Alpha lebih kecil dari 0,70, maka kuesioner sebagai alat pengukur dinyatakan tidak reliabel. Untuk hasil uji reliabilitas dapat diketahui bahwa variabel budaya organisasi memiliki nilai Cronbach Alpha sebesar $(0,861)>$ Apha standar $(0,70)$ sehingga dinyatakan reliable. Demikian pula variabel employee engagement $(\mathrm{Y})$ memiliki nilai Cronbach Alpha sebesar $(0,851)>$ Alpha standar $(0,70)$ sehingga dinyatakan reliable. Dengan demikian indikator-indikator pada variabel budaya organisasi dan employee engagement menjadi indikator yang layak untuk digunakan dalam penelitian ini.

\section{Analisis Regresi Linier Sederhana}

Hasil analisis regresi linier sederhana untuk variabel budaya organisasi (X) terhadap employee engagement $(\mathrm{Y})$ adalah sebagai berikut:

Tabel 4. Hasil Analisis Regresi Linier Sederhana

Coefficients $^{\mathbf{a}}$

\begin{tabular}{llr|r|r|r|r}
\hline & \multirow{2}{*}{ Model } & \multicolumn{2}{c}{ Unstandardized Coefficients } & Standardized Coefficients & \multirow{2}{*}{ t } & \multirow{2}{*}{ Sig. } \\
& \multicolumn{1}{c}{ B } & Std. Error & Beta & & 4.097 & 0.000 \\
\hline 1 & (Constant) & 17.704 & 4.321 & 0.659 & 5.035 & 0.000 \\
\cline { 2 - 9 } & Budaya Organisasi & 0.613 & 0.122 & & 0.035 \\
\hline
\end{tabular}

a. Dependent Variable: Employee Engagement

Sumber: Data Primer Diolah 2020.

Berdasarkan Tabel 4 di atas persamaan regresi adalah : $\mathrm{Y}=17,704+0,613 \mathrm{X}$ menyatakan bahwa jika tidak ada kenaikan nilai dari variabel budaya organisasi (X), nilai employee engagement (Y) adalah 17,704. Sedangkan pada variabel budaya organisasi (X) mempunyai koefisien regresi sebesar 0,613 , artinya setiap penambahan satu nilai pada variabel budaya organisasi (X) akan meningkatkan employee engagement (Y) sebesar 0,613. Dan nilai signifikansinya sebesar $0,000<0,05$ maka nilai koefisien regresi variabel budaya organisasi (X) signifikan untuk menjadi prediksi nilai employee engagement (Y) pada karyawan BAAK Universitas XYZ di Jakarta.

\section{Pengujian Hipotesis Dengan Menggunakan Uji t}

Pengujian hipotesis variabel budaya organisasi $(\mathrm{X})$ terhadap employee engagement $(\mathrm{Y})$ adalah sebagai berikut:

$\mathrm{H}_{0}: \beta=0$ Artinya budaya organisasi (X) tidak berpengaruh terhadap employee engagement $(\mathrm{Y})$ pada karyawan BAAK Universitas XYZ di Jakarta.

$\mathrm{H}_{\mathrm{a}}: \beta \neq 0$ Artinya budaya organisasi (X) berpengaruh terhadap employee engagement (Y) pada karyawan BAAK Universitas XYZ di Jakarta.

Untuk menentukan nilai $t_{\text {tabel }}$ diperoleh dari derajat kebebasan yaitu $\mathrm{df}=\mathrm{n}-2$ atau $35-2=33$ ( $\mathrm{n}$ adalah jumlah sampel), $\alpha=5 \%$, karena merupakan uji 2 sisi maka $\alpha / 2=5 \% / 2=2,5 \%$ atau 0,025 , sehingga $t_{\text {tabel }}=2,034$.

Pengambilan keputusannya adalah jika $t_{\text {hitung }} \leq t_{\text {tabel }}$, maka $\mathrm{H}_{0}$ diterima, artinya budaya organisasi $(\mathrm{X})$ tidak berpengaruh terhadap employee engagement $(\mathrm{Y})$ pada karyawan BAAK Universitas $X Y Z$ di Jakarta. Jika $t_{\text {hitung }}>t_{\text {tabel }}$, maka $\mathrm{H}_{0}$ ditolak, artinya budaya organisasi (X) berpengaruh terhadap employee engagement $(\mathrm{Y})$ pada karyawan BAAK Universitas XYZ di Jakarta. 
Berdasarkan Tabel 1.4 di atas dapat diketahui bahwa $t_{\text {hitung }}(5,035)>t_{\text {tabel }}(2,034)$ jadi $H_{0}$ ditolak dan $\mathrm{H}_{\mathrm{a}}$ diterima, artinya budaya organisasi (X) berpengaruh terhadap employee engagement $(\mathrm{Y})$ pada karyawan BAAK Universitas XYZ di Jakarta, sehingga hipotesis yang menyatakan bahwa budaya organisasi $(\mathrm{X})$ berpengaruh positif dan signifikan terhadap employee engagement (Y) pada karyawan BAAK Universitas XYZ di Jakarta, terbukti.

Hasil penelitian di atas sejalan dengan hasil penelitian (Akbar, 2013) dan (Anugra \& Saragih, 2018) bahwa budaya organisasi mempengaruhi employee engagement. Apabila budaya perusahaan sesuai dengan ekspektasi karyawan maka engagement dari karyawan akan tinggi, begitu juga sebaliknya apabila budaya dalam perusahaan tersebut tidak sesuai ekspektasi dari karyawan maka engagement dari karyawan akan rendah.

\section{Uji Koefisien Determinasi $\left(R^{2}\right)$}

Hasil uji koefisien determinasi $\left(\mathrm{R}^{2}\right)$ dapat dilihat pada Tabel 5 di bawah ini:

Tabel 5. Hasil Uji Koefisien Determinasi Model Summaryb

\begin{tabular}{ll|lr|r}
\hline Model & R & R Square & Adjusted R Square & Std. Error of the Estimate \\
\hline 1 & $0.659^{\mathrm{a}}$ & 0.434 & 0.417 & 3.215 \\
\hline a. Predictors: (Constant), Budaya Organisasi & & \\
b. Dependent Variable: Employee Engagement & \\
Sumber: Data Primer Diolah 2020.
\end{tabular}

Dari hasil pengujian di atas diperoleh nilai koefisien determinasi $\left(\mathrm{R}^{2}\right)$ sebesar 0,434 . Jadi sumbangan pengaruh dari variabel budaya organisasi $(\mathrm{X})$ terhadap employee engagement $(\mathrm{Y})$ pada karyawan BAAK Universitas XYZ di Jakarta adalah sebesar 43,4\%, sedangkan sisanya $(100 \%-43,4 \%=56,6 \%)$ dipengaruhi oleh faktor lain yang tidak diteliti seperti pekerjaan itu sendiri, lingkungan kerja, kepemimpinan dalam organisasi, kesempatan untuk berkontribusi dan berkembang (Armstrong, 2008).

\section{Kesimpulan dan Saran}

\section{Kesimpulan}

Berdasarkan hasil penelitian yang telah dilakukan mengenai pengaruh budaya organisasi terhadap employee engagement pada karyawan BAAK Universitas XYZ di Jakarta, maka dapat diambil beberapa kesimpulan sebagai berikut:

a. Hasil analisis deskriptif terhadap variabel budaya organisasi dan employee engagement menunjukkan rata-rata skor yang tinggi, hal ini berarti bahwa semakin baik penerapan budaya organisasi pada karyawan maka semakin tinggi pula employee engagement-nya.

b. Hasil pengujian hipotesis (uji t) menunjukkan bahwa budaya organisasi berpengaruh positif dan signifikan terhadap employee engagement pada karyawan BAAK Universitas XYZ di Jakarta karena diketahui nilai $t_{\text {hitung }}(5,035)>t_{\text {tabel }}(2,034)$ dan nilai signifikansinya sebesar $0,000<0,05$.

c. Hasil pengujian koefisien determinasi $\left(\mathrm{R}^{2}\right)$ juga menunjukkan bahwa sumbangan pengaruh dari variabel budaya organisasi terhadap employee engagement pada karyawan BAAK Universitas XYZ di Jakarta adalah sebesar 43,4\%.

\section{Saran}

Berdasarkan kesimpulan di atas maka disarankan agar diperhatikan hal-hal yang berkaitan dengan budaya organisasi karena berdasarkan hasil analisis yang diuraikan sebelumnya memiliki pengaruh yang positif dan signifikan terhadap employee engagement. Dalam pengisian angket yang disebarkan melalui google form, terdapat responden yang memberikan saran dan komentar bahwa karyawan BAAK Universitas XYZ di Jakarta masih kurang menghargai satu sama lain. 
Disamping itu juga, responden berharap, setiap pekerjaan yang dikerjakan dapat didukung oleh unit-unit terkait. Oleh sebab itu, hal-hal tersebut perlu diperhatikan agar kedepannya menjadi lebih baik dan dapat meningkatkan employee engagement, karena karyawan yang engaged akan memiliki keyakinan dan mendukung tujuan organisasi, memiliki rasa memiliki, merasa bangga terhadap organisasi dimana dia bekerja dan mempunyai keinginan untuk berkembang dan bertahan dalam organisasi.

Selain itu, aspek-aspek yang perlu diperhatikan terkait dengan employee engagement adalah pekerjaan yang dikerjakan oleh karyawan, kepemimpinan dalam organisasi, kesempatan karyawan untuk berkontribusi dan berkembang karena karyawan yang engage adalah seseorang yang berpikir positif tentang pekerjaannya; percaya pada apa yang dilakukannya dan mengidentifikasinya dengan organisasi; bekerja secara aktif untuk membuat segalanya lebih baik; memperlakukan orang lain dengan hormat, dan membantu rekan kerja untuk bekerja lebih efektif; dapat diandalkan, dan melampaui persyaratan pekerjaan; melihat gambaran yang lebih besar, bahkan terkadang mengeluarkan biaya pribadi untuk kepentingan organisasi; mengikuti perkembangan di bidangnya; mencari, dan diberikan kesempatan untuk meningkatkan kinerja organisasi.

\section{Daftar Pustaka}

Akbar, R. M. (2013). Pengaruh Budaya Organisasi terhadap Employee Engagement (Studi pada Karyawan PT. Primatexco Indonesia di Batang). Journal of Social and Industrial Psychology, Vol. 2. No. 1. http://journal.unnes.ac.id/sju/index.php/sip

Albrecht, S. L. (2010). Handbook of Employee Engagemt: Perspectives, Issues, Research and Practice. Edward Elgar.

Anugra, A. T., \& Saragih, R. (2018). Pengaruh Budaya Organisasi terhadap Employee Engagement di PT. Asuransi Jasa Indonesia Cabang Bandung Ritel. ALMANA, Vol. 2 No. 3, hal. 100-107, http://journalfeb.unla.ac.id/index.php/almana/article/view/156

Armstrong, M. (2008). Strategy Human Resource Management, Fourth edi, Kogan Page. https://englishcele.gnomio.com/pluginfile.php/62/mod_resource/content $/ 2 /$ Armstrong_SH RM_Action.pdf

Budihardjo, A. (2011). Organisasi Menuju Pencapaian Kinerja Optimum - Google Books. Prasetiya Mulya Business School. https://www.google.co.id/books/edition/Organisasi/gzp3DAAAQBAJ?hl=id\&gbpv=1\&dq $=$ keterikatan+karyawan\&pg $=\mathrm{PA} 165 \&$ printsec $=$ frontcover

Ermawati, N. P. D., \& Ardana, I. K. (2018). Pengaruh Kepemimpinan Transformasional, Budaya Organisasi dan Motivasi Terhadap Komitmen Organisasional Pada BPR Di Kabupaten Klungkung. E-Jurnal Manajemen Universitas Udayana, Vol. 7 No. 11, hal. 6326-6359.

Khairunisa, S. K. (2018). Pengaruh Kepemimpinan Transformasional dan Budaya Organisasional terhadap Employee Engagement.

Kreitner, R., \& Kinicki, A. (2005). Perilaku Organisasi. Buku 1 (Edisi Keli). Jakarta: Salemba Empat.

Othman, A. K., Hamzah, M. I., Abas, M. K., \& Zakuan, N. M. (2017). The influence of leadership styles on employee engagement: The moderating effect of communication styles, International Journal of Advanced and Applied Sciences. Vol 4 No. 3, hal. 107-116.

Priyatno, D. (2008). Mandiri Belajar SPSS (Statistical Product and Service Solution) Untuk AnalisisData \& Uji Statistik. MediaKom.

Robbins, S. P., \& Judge, T. A. (2002). Organizational Behavior, concepts, theories and applications. Tehran: Institute of Commercial Researches.

Robbins, S.P, \& Judge, T. A. (2008). Perilaku Organisasi 1 (ed. 12) HVS - Google Books. Salemba

Empat. https://www.google.co.id/books/edition/Perilaku_Organisasi_1_ed_12_HVS/IwrWupB1rC $4 \mathrm{C} ? \mathrm{hl}=\mathrm{id} \& \mathrm{gbpv}=1 \& \mathrm{dq}=$ keterlibatan + karyawan $+($ employee+engagement $) \& \mathrm{pg}=\mathrm{PA} 103 \& \mathrm{pr}$ 
intsec $=$ frontcover

Sarjono, H., \& Julianita, W. (2011). SPSS vs LISREL Sebuah Pengantar, Aplikasi untuk Riset. Salemba Empat.

Schein, E. H. (2010). Organizational Culture and Leadership (4th ed.). Jossey-Bass.

Sekaran, U. (2015). Research Methods For Business Metode Penelitian untuk Bisnis (R. Widyaningrum (ed.); 4th ed.). Salemba Empat.

Setiawan, B., \& Muntaha, A. (2014). Unsur-unsur Fundamental Penelitian Sosial.

Suliyanto, S. (2018). Metode Penelitian Bisnis untuk Skripsi, Tesis, \& Disertasi. Andi Offset.

Sutrisno, H. E. (2010). Budaya Organisasi. Jakarta: Prenadamedia Group. https://www.google.co.id/books/edition/Budaya_Organisasi/pd6VDwAAQBAJ?hl=id\&gb $\mathrm{pv}=1 \& \mathrm{dq}=$ budaya + organisasi\&printsec $=$ frontcover

Wijaya, T. (2013). Metode Penelitian Ekonomi dan Bisnis. Graha Ilmu. 